\title{
Mais e melhores relacionamentos: uma proposta de metodologia de gestão da comunicação em arranjos produtivos locais ${ }^{1}$
}

\author{
Rosa Lima**
}

\begin{abstract}
Resumo O trabalho apresenta uma proposta de metodologia de gestão do relacionamento em arranjos produtivos locais (APLs), visando uma melhor comunicação entre seus agentes. Ele parte do pressuposto de que vivemos uma nova realidade, marcada pela preponderância da informação, do conhecimento e de organizações em rede. Nesse contexto, os ativos intangíveis passam a ter peso fundamental na competitividade das organizações e precisam ser levados em conta em sua gestão. A metodologia apresentada, baseada nos conceitos de "capitais do conhecimento" e "redes de valor", tem por objetivo adensar os fluxos de informação e conhecimento entre os diversos agentes de um APL, através de uma melhor gestão do relacionamento entre eles.
\end{abstract}

Palavras-chave informação, conhecimento, redes, gestão do relacionamento, desenvolvimento local

\begin{abstract}
The article presents a proposal of methodology for the management of relationship capital in clusters, aiming at a more fluid communication process among its agents. It is based on the assumption that we live in a new reality, marked by the relevance of information, knowledge and network organizations. In this context, intangible assets play a major role in the competitiveness of the organizations and need to be taken into account in its management. The main purpose of the methodology presented, based in the concepts of "knowledge capitals" and "value networks", is to make information and knowledge flows easier among the various agents of a cluster, by managing of the relationship between them in a more efficient way.
\end{abstract}

Keywords information, knowledge, networks, relashionship management, local development

\section{Introdução}

Vivemos hoje um momento inédito na história da humanidade, marcado por três características fundamentais: o papel estratégico da informação na vida econômica e social, o posicionamento do conhecimento como principal fator de produção e a predominância das organizações em rede.

\footnotetext{
${ }^{1}$ Este artigo foi baseado na dissertação "Novas lentes para uma nova realidade: uma proposta de metodologia de gestão do capital de relacionamento em Arranjos Produtivos Locais", defendida em março de 2006 como requisito para a obtenção do grau de mestre em ciências em Engenharia de Produção pela Coppe/UFRJ

* Mestre em Engenharia de Produção pela Coppe/UFRJ e coordenadora de comunicação do Centro de Referência em Inteligência Empresarial (Crie), Coppe/UFRJ
} 
Essas características, no entanto, pouco vêm sendo levadas em conta no desenho das políticas públicas que visem o desenvolvimento sustentável, em geral, e nos planos de ação que busquem aumentar a competitividade dos arranjos produtivos locais (APLs), em particular.

A literatura sobre aglomerações produtivas tem demonstrado que uma das chaves para o seu sucesso está na forte interação entre os membros dessa rede, ou seja, entre as empresas e também entre elas e as instituições de apoio locais e o ambiente mais amplo em que se inserem. Seria esse um dos principais diferenciais que esses aglomerados de micro, pequenas e médias empresas trariam em termos de eficácia, para fazer frente à economia de escala das grandes unidades de produção.

Porém, ainda são muitas as lacunas no sentido de se definirem metodologias capazes de mapear os fluxos de informação e comunicação e identificar as trocas de conhecimento e de benefícios intangíveis presentes nesses APLs, de forma a possibilitar a formulação de estratégias que visem fortalecer os laços de interação entre os agentes que ali atuam.

Este trabalho procura reduzir essas lacunas, propondo a adoção de um instrumento de pesquisa empírica que possibilite captar e analisar esses fluxos e essas trocas, permitindo uma melhor gestão do capital de relacionamento dos arranjos produtivos locais. Ou seja, permitindo que se formulem estratégias para uma melhor interação entre as empresas ali presentes e também entre elas e os demais atores (governos, agências de fomento, instituições financeiras, entidades de classe, centros de pesquisa, etc.) que compõem aquele arranjo, de forma a aumentar sua competitividade.

Se a possibilidade de compartilhar conhecimento é a maior vantagem trazida pela formação das redes em geral, e, por conseguinte, pela constituição de um arranjo produtivo, entendemos que um dos grandes desafios para sua maior competitividade está justamente na abertura de mais canais de comunicação e no estímulo a mais e melhores relacionamentos entre os elos que compõem a rede.

A proposta de metodologia aqui apresentada, de gestão do capital de relacionamento de um APL, é baseada num modelo de Gestão do Conhecimento, denominado "capitais do conhecimento", desenvolvido por pesquisadores do Centro de Referência em Inteligência Empresarial (Crie), da Universidade Federal do Rio de Janeiro (UFRJ) e no conceito de rede de valor, elaborado por Verna Allee (2000).

Parte-se do pressuposto de que uma organização, assim como qualquer pessoa, só se relaciona com outra se aquele relacionamento tiver algum sentido ou algum valor para ela. Valor numa acepção ampla, não apenas valor monetário. Por isso mesmo, ela só terá interesse em estreitar relações com essa outra organização se conseguir perceber o valor daquele relacionamento para ela própria. A partir da compreensão das lacunas existentes entre as trocas de valor potenciais de bens, serviços, renda, mas também de informação, conhecimento e benefícios intangíveis, como confiança, fidelidade, etc - e as trocas reais de valor entre as organizações, é que se pode partir para estratégias e planos de ação em prol de um relacionamento mais profícuo entre elas.

Um exemplo de análise do Arranjo Produtivo Local de Nova Friburgo e Região, no Estado do Rio de Janeiro, à luz desse instrumento, é apresentado como caso ilustrativo de aplicação da metodologia. Ele não pretende ser um estudo de caso exaustivo sobre o pólo de moda íntima da Região Centro-Norte fluminense, objeto de interesse e apoio de diversas instituições de fomento nacionais e internacionais. Visa apenas ilustrar a aplicabilidade da metodologia, mostrando como 
uma mesma realidade, vista por novas lentes, pode se revelar muito diferente da que se apresenta através dos velhos instrumentos de análise ainda em uso.

\section{Novas lentes para uma nova realidade}

A nova realidade em que vivemos impõe-nos a necessidade de lançarmos mão de novas lentes para a compreensão dos desafios impostos a nossa sociedade, na busca de padrões mais sustentáveis de desenvolvimento.

Se, no mundo atual, a informação, o conhecimento e a inovação são os principais geradores de riqueza, são esses ativos que precisam ser gerenciados prioritariamente para que as organizações sejam bem-sucedidas. É a isso que se propõe a inteligência empresarial, conceito que sintetiza o estado da arte da gestão de empresas na sociedade do conhecimento. Ela diz respeito à capacidade de uma organização de gerenciar seus ativos (tangíveis e intangíveis) levando em conta o tripé conhecimento, inovação e empreendedorismo (CAVALCANTI; GOMES; PEREIRA, 2001).

Para realizar a gestão da inovação, uma organização precisa gerenciar não apenas o conhecimento explícito interno, mas o conhecimento inerentemente subjetivo e presente dentro e fora das organizações, o conhecimento tácito, colocando-os ambos a serviço dos diversos níveis de tomada de decisão, desde as decisões pulverizadas do dia-a-dia até as grandes diretrizes corporativas, valorizando-os como mais um ativo do conjunto de capitais da empresa. Não se pode falar de gestão da inovação sem falar na gestão do conhecimento, e vice-versa.

Pesquisadores do Centro de Referência em Inteligência Empresarial (Crie), da Universidade Federal do Rio de Janeiro (UFRJ) desenvolveram um modelo para gestão das organizações na sociedade do conhecimento, denominado capitais do conhecimento (CAVALCANTI; GOMES; PEREIRA, 2001). Este modelo é composto por quatro capitais que devem ser devidamente monitorados e gerenciados para a efetiva gestão do conhecimento de uma organização. São eles: capital ambiental, capital estrutural, capital humano e capital de relacionamento, que podem ser visualizados no diagrama abaixo (Figura 1).

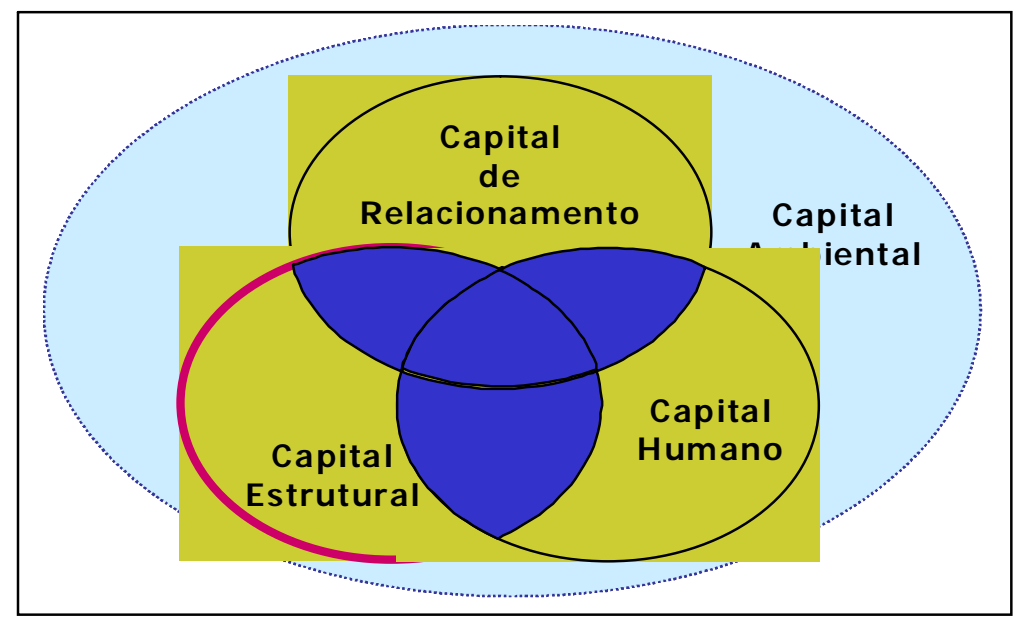


Figura 1: Os capitais do conhecimento

Fonte: Crie/Coppe/UFRJ. CAVALCANTI; GOMES; PEREIRA, 2001.

O capital ambiental é definido como o conjunto de fatores que descrevem o ambiente onde a organização está inserida. Nenhuma organização pode existir sem saber onde está nem aonde quer chegar, o que significa ter uma definição muito clara da sua estratégia e do seu posicionamento no mercado. Além disso, é indispensável estar atenta às mudanças, ser flexível, perceber as inovações tecnológicas e, principalmente, entender que informação e conhecimento são fatores estratégicos.

O capital estrutural corresponde à infra-estrutura necessária para fazer a organização funcionar, ou seja, é o conjunto de sistemas administrativos, conceitos, marcas, patentes, modelos, rotinas, processos, programas de computador e tudo mais que fica na instituição quando as pessoas vão embora. Também faz parte do capital estrutural a forma de uma organização trabalhar, ou seja, sua cultura organizacional. Já o capital humano refere-se tanto à capacidade, à habilidade e à experiência quanto ao conhecimento formal, os valores e as redes sociais das pessoas que integram uma organização.

Por fim, o capital de relacionamento refere-se à maneira como a organização se relaciona com os diversos atores que compõem o ambiente onde ela atua. $\mathrm{O}$ capital de relacionamento, no conceito elaborado pelo Crie, não se resume às relações das empresas com seus clientes apenas, mas com todos os atores com quem ela estabelece relações para a realização de seu negócio, sejam eles empresas parceiras, fornecedores, instituições financeiras, agências de fomento, institutos de pesquisa, governo, meios de comunicação ou grupos de interesse.

Esses diversos relacionamentos de uma organização compõem o que Verna Allee denominou de rede de valor (ALLEE, 2000). A rede de valor é uma teia de relacionamentos sociais e de negócios que possibilita a troca justa de bens tangíveis e intangíveis, serviços e benefícios. Uma rede de valor gera valor econômico servindo-se de trocas dinâmicas complexas entre um ou mais empreendimentos, consumidores, fornecedores, parceiros estratégicos e a comunidade. São redes que envolvem mais do que apenas transações de bens, serviços e renda. Além de produtos físicos, serviços e dinheiro, é possível trocar informação e conhecimento por um bem intangível, como fidelidade a uma marca, imagem positiva na comunidade, etc. ualquer organização ou grupo de organizações engajadas em trocas tanto de tangíveis quanto de intangíveis pode ser vista como uma rede de valor, seja uma empresa privada, uma empresa do setor público ou um governo. Portanto, a chave para reconfigurar os modelos de negócio para a economia do conhecimento está na compreensão das novas moedas de valor, a saber:

- Bens, serviços e renda - (as moedas tradicionais da cadeia de valor) - Trocas diretas de serviços, entrega de bens, serviços, contratos, faturas e pedidos e retornos de ordens de pagamento, solicitações de propostas e confirmações de pagamentos.

- Conhecimento - Troca de informação estratégica, conhecimento sobre planejamento, conhecimento de processo, projetos colaborativos que fluem em torno da cadeia central de valor de produtos e serviços e a sustentam. Trata-se aqui de trocas de conhecimento explícito, trocas de informação. 
- Benefícios intangíveis - Trocas de conhecimento tácito e benefícios que vão além do produto ou serviço em si e não são levados em conta na contabilidade tradicional, tais como senso de comunidade, fidelidade dos clientes, confiança, reforço de imagem ou oportunidades de uso conjunto de marcas.

Essas trocas de moedas de valor estão no cerne da rede de valor. Onde quer que haja uma transação num empreendimento complexo, há uma troca de valor de um ou mais desses três tipos. Cada troca é sustentada por algum mecanismo ou meio que permita que ela aconteça. As trocas diretas de serviços, bens e renda são apenas parte do quadro, e nem sempre são a mais importante para o sucesso do empreendimento. O valor do conhecimento e o valor do benefício intangível têm a mesma (e algumas vezes mais) importância, e o sucesso depende de se construir uma rica teia de relacionamentos de confiança. Valores essenciais como integridade, honestidade, responsabilidade, inclusão e respeito contribuem de forma intensa na criação de um ambiente propício às trocas justas entre os membros da rede.

\section{Metodologia de gestão do capital de relacionamento em APLs}

Como vimos, o capital de relacionamento de uma organização refere-se à maneira como ela se relaciona com os diversos atores que compõem seu ambiente de atuação. A partir da sua visão estratégica, a empresa deve determinar os relacionamentos-chave para o sucesso de seu negócio e construir uma estratégia de relacionamento com cada um deles.

Como estamos tratando de arranjos produtivos locais (APLs) - ou seja, de redes de pequenas empresas, eventualmente estruturadas em torno de outras de maior porte, envolvidas na produção e/ou comercialização de bens e serviços em um determinado território, visando a seu desenvolvimento - a visão estratégica que importa é a da própria rede e não a das empresas ali inseridas isoladamente.

Assim, a gestão do capital de relacionamento do APL terá que necessariamente contemplar as relações entre as empresas que compõem o arranjo, entre essas e o ambiente institucional onde elas atuam e ainda as relações que se estabelecem entre o arranjo como um todo e o ambiente externo a ele, ou seja, os mercados local, regional, nacional e internacional com os quais ele estabelece relações.

A maior parte das organizações, incluindo os APLs, recorre atualmente a alguma ferramenta de comunicação para se relacionar com seus públicos interno e externo, seja utilizando meios digitais ou veículos tradicionais. A difusão das tecnologias de informação e comunicação tem permitido a utilização de uma gama ampla de ferramentas, veículos e serviços como call-centers, websites, portais, "fale conosco", fóruns, listas de discussão, comunidades virtuais, blogs, emails, messengers, voice-mails, entre outros, que de fato oferecem um enorme potencial de estreitamento de relações entre as organizações e seus diversos clientes. Mas elas não fazem isso per se.

Ainda são poucas as organizações, e os APLs em particular, que conseguem ultrapassar o estágio institucional e de divulgação em seus sites, para citar apenas um único exemplo. São muito poucas as que conseguem explorar as oportunidades oferecidas pela interatividade característica 
da internet. Com isso, desperdiçam o potencial que essa mídia oferece para aprender mais sobre seus clientes e tirar melhor proveito de suas relações com eles.

Mas o que é pior é que muitas vezes as organizações adotam tecnologias de comunicação sem ao menos saber por que o estão fazendo. Qualquer política ou plano de ação para ser eficaz e eficiente deve estar embasado num diagnóstico preciso e este em informações e dados confiáveis e atualizados. Da mesma forma, a decisão pela adoção de uma tecnologia precisa estar vinculada aos objetivos estratégicos da organização para produzir resultados consistentes.

Mas o que ocorre de fato é que essas ferramentas muitas vezes são adotadas sem nenhuma vinculação com os objetivos estratégicos da organização, com resultados muito limitados em termos do incremento de sua competitividade. Veículos de comunicação, em particular a internet, são componentes fundamentais no novo ambiente de negócios em que vivemos, mas não têm um valor em si mesmos para as organizações. Tecnologias de informação e comunicação são ferramentas, instrumentos, veículos ou meios que ajudam as organizações a atingirem objetivos. Não são um fim em si mesmas.

Portanto, é preciso ter claro, primeiramente, que objetivos são esses que se quer atingir e de que forma uma melhor interação com aqueles que a organização mantém relacionamentos-chave pode contribuir para se atingir esses objetivos. Nossa proposta é que isso se faça através de um cuidadoso plano de gestão do capital de relacionamento, que contemple toda a rede de atores que mantenham relações estratégicas para o sucesso do APL. Qualquer proposta de relacionamento entre esses atores deve ser planejada e estruturada cuidadosamente de forma a possibilitar mais e melhores trocas de valor para a rede como um todo.

A adoção de ferramentas, a nosso ver, é uma decisão que só faz sentido a posteriori, ou seja, depois que a estratégia de relacionamentos é definida. E essa estratégia, por sua vez, só pode ser definida quando se conhecem os relacionamentos-chave para o sucesso de um negócio, isto é, quando se determinam as necessidades das trocas (de bens e produtos, de conhecimento e de benefícios intangíveis) entre os atores, as trocas efetivamente existentes entre eles, e as lacunas entre os dois. É por este motivo que a proposta de metodologia aqui apresentada faz uso do conceito de rede de valor proposto por Allee (2000).

A primeira questão, assim, é identificar e caracterizar os atores-chave com os quais a organização precisa se relacionar para a sua boa atuação no mercado. No caso dos arranjos produtivos locais, a identificação e caracterização dos atores-chave é particularmente importante, por se tratar de ambientes que não apenas são propícios a interações, mas dependem dela para se manterem no mercado.

De uma maneira resumida, as trocas de valor num APL podem envolver os seguintes atores (ALBAGLI; MACIEL, 2004):

- agentes econômicos - clientes, competidores e parceiros; fornecedores de insumos, componentes, máquinas ou equipamentos; fornecedores de serviços diversos; distribuidores, vendedores, instituições financeiras, consumidores finais, etc;

- agentes institucionais - organizações de suporte, agências de fomento, agências de exportação, associações empresariais, sindicatos e demais entidades de classe, organizações não-governamentais; etc;

- agentes de regulação - governos, Poder Judiciário, agências reguladoras, etc; 
- agentes de conhecimento - universidades, institutos e centros de pesquisa, consultores, etc;

Essa pluralidade de agentes presentes num APL contribui para que sejam geradas trocas intensas de valor entre eles e o ambiente onde atuam propiciando vários fluxos de conhecimento e aprendizado interativo. Mas se a proximidade espacial entre os agentes que ali se verifica facilita a comunicação e, portanto, uma maior interação e mais trocas de valor, por si só ela não é garantia de que isso ocorra. São necessárias outras condições - econômicas, sociais e institucionais - que as favoreçam, e muitas vezes, a adoção de políticas e ações específicas que as estimulem.

Em função disso, nossa proposta de gestão do capital de relacionamento em um arranjo produtivo local compreende a análise das trocas de todas as moedas de valor (de bens, serviços e renda; de conhecimento; e de benefícios intangíveis) entre todos os atores-chave da rede e deve envolver três fases distintas, a saber:

- Definição das trocas de valor necessárias entre os atores da rede para o sucesso do negócio - Para isso, é preciso desenhar a rede de valor do APL, identificando todos os seus atores, ou seja, todos os relacionamentos que são chaves (estratégicos) para o negócio do APL e as trocas de valor (tangíveis e intangíveis) potenciais e estratégicas que pode haver entre eles.

- Mapeamento das trocas de valor existentes na rede - Uma vez identificados todos os atores da rede e as trocas de valor que deveria haver entre eles para melhorar a competitividade do APL, parte-se para um diagnóstico da realidade da rede, isto é, vai-se mapear as trocas que de fato ocorrem entre os membros da rede.

- Identificação das lacunas nas trocas de valor da rede - Comparando-se as trocas ideais entre os membros da rede com as que ocorrem realmente, chega-se a um mapa das lacunas ou das falhas existentes nas trocas de valor da rede.

Nessa perspectiva, a instância de governança do APL pode perceber a importância de investir em mecanismos que propiciem maior interação entre os atores da rede, de forma a possibilitar maiores trocas de conhecimento e intangíveis. Quando se tem clara a distância entre o que se quer e o que se tem, pode-se partir para a construção de estratégias de relacionamento que permitirão à organização, no caso, o arranjo produtivo local, se articular melhor tanto internamente quanto no ambiente institucional e mercadológico em que está inserido.

Somente a partir desse diagnóstico é que será desenhado um plano de gestão do capital de relacionamento, visando estreitar as relações entre os atores da rede. É nele que se vai estruturar um plano de ação e definir as ferramentas que poderão ser utilizadas com o fim de se estabelecer relacionamentos de maior valor na rede.

O plano de gestão do relacionamento deve contar com ações de curto prazo, para mostrar à sociedade e aos membros da rede que a gestão do capital de relacionamento pode dar resultados concretos; de médio prazo, mais voltados para a resolução de problemas estruturais; e projetos mais de longo prazo, voltados para a sistematização de processos e a consolidação da rede. 


\section{Um caso ilustrativo: o APL de Nova Friburgo e Região, RJ}

Vamos, agora, tomar como exemplo um arranjo produtivo local específico e mostrar de que forma a metodologia proposta pode ser aplicada e que estratégias e planos de ação podem advir de sua análise. O APL escolhido foi o de moda íntima, situado em Nova Friburgo e Região, no Estado do Rio de Janeiro. As informações que se seguem foram colhidas em documentos sobre o pólo, em visitas ao município de Nova Friburgo e em conversas informais com representantes do APL.

A nova configuração produtiva industrial de Nova Friburgo e dos demais municípios que compõem o pólo de moda íntima traz novos e grandes desafios para o desenvolvimento local. Se antes ele dependia de poucas e grandes empresas, hoje ele é gerado por um enorme contingente de micro e pequenas empresas, muitas das quais informais e com baixa capacidade gerencial, aumentando sobremaneira a complexidade das relações entre elas. Ainda são muitos os problemas de governança entre as diversas instituições públicas e privadas que prestam serviços às empresas e persistem problemas de organização espacial e de capacitação.

De acordo com Fauré e Hasenclever (2005), a maior parte das empresas (73\%) presentes no pólo de moda íntima de Friburgo não estabelece cooperação com outras empresas. As principais cooperações registradas se estabelecem verticalmente - isto é, entre as empresas fornecedoras e as clientes - e não horizontalmente, no mesmo mercado, à exceção do consórcio de exportação, experimentado por $20 \%$ das empresas do pólo. Entre as empresas informais, não se registra nenhuma cooperação.

A principal hipótese desses estudiosos para se explicar esse padrão de cooperação é a falta de complementaridade entre as empresas desse setor. Elas são fortemente verticalizadas e concorrem no mesmo mercado final. Todas realizam praticamente as mesmas funções e o grau de especialização entre elas é muito pequeno.

Segundo estudo do Senai/RJ (Apud LAUFER; FURTADO; BATISTA NETO, 2005), 87,8\% do mercado concorrente para o APL de Nova Friburgo localiza-se dentro do pólo, ou seja, a maioria dos produtores de moda íntima de Friburgo identifica as empresas do próprio pólo como seus maiores concorrentes.

Esse ambiente empresarial de baixa cooperação verificado em Nova Friburgo e Região desenha um cenário pouco alvissareiro para o APL. A maioria das empresas do pólo de moda íntima não possui massa crítica para competir isoladamente em mercados cada vez mais exigentes e complexos. O maior desafio do estabelecimento de uma organização virtuosa entre as empresas, as instituições e os poderes públicos, no caso do APL de Friburgo, é organizá-los em torno de um projeto de interesses convergentes que favoreçam o compartilhamento do conhecimento possibitado pela organização em rede. A convergência de interesses decorre de objetivos comuns e visões compartilhadas de desenvolvimento local (FAURÉ; HASENCLEVER, 2005).

Para que este compartilhamento ocorra, é preciso que todos os atores do APL tenham claro o valor que as trocas no pólo podem trazer para si e para o coletivo. Nesse sentido, a metodologia de gestão do capital de relacionamento apresentada cumpre justamente o papel de evidenciar as trocas necessárias e as lacunas existentes, e assim permitir o desenho de estratégias para potencializar as trocas de valores e estreitar os relacionamentos entre os agentes. 
O APL de Nova Friburgo é uma rede de trocas complexas e dinâmicas que envolve diversos atores, formando parcerias que se modificam de acordo com o objetivo da ação planejada. Portanto, para fazer o mapeamento da rede de valores, é preciso primeiramente fazer um levantamento prévio de como é a operação do APL e quais são as organizações que, de alguma forma, nele atuam.

Identificamos os seguintes atores com relacionamentos estratégicos no pólo de moda íntima:

- $\quad$ agentes econômicos - empresas de confecção, fornecedores, distribuidores, revendedores diretos ("sacoleiras"), varejistas, consumidores finais, Banco do Brasil, BNDES, BID, etc;

- $\quad$ agentes institucionais - Conselho da Moda, Firjan, Sebrae, Núcleo de Apoio ao Design (NAD)/Senai, Sindvest, Finep, consórcio de exportação;

- $\quad$ agentes de regulação - governo federal, governo do Estado do Rio, governos municipais das cidades envolvidas, Poderes Legislativo e Judiciário;

- $\quad$ agentes de conhecimento - Uerj, UFRJ e consultores.

Como pode ser visto na Figura 2, existe um número muito grande de instituições atuando no pólo, incentivando o seu desenvolvimento. Essas instituições trocam tanto valores tradicionais bens, serviços e renda, quanto valores intangíveis, tais como informações, conhecimento, experiência, capacitação, satisfação, reforço de imagem, confiança, etc.

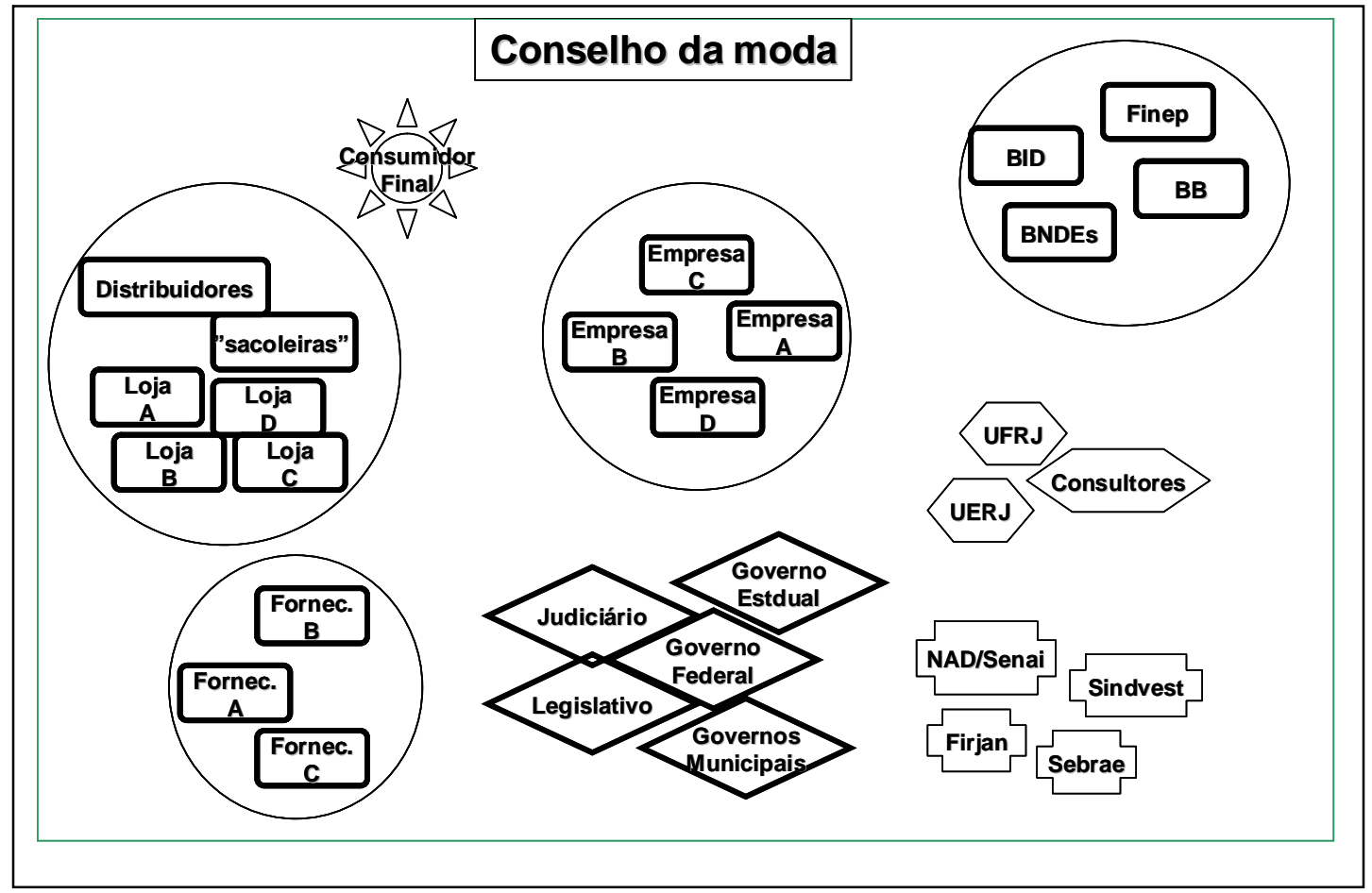

Figura 2 - Os atores da rede de valor do APL de Nova Friburgo

Fonte: Própria 
Tomemos, agora, como exemplo, as trocas de moedas de valor efetuadas entre duas empresas de confecção presentes no pólo. A empresa A produz lingerie da linha dia e a empresa B trabalha com lingerie da linha noite.

\section{Mapeamento das trocas necessárias e potenciais (Figura 3):}

- Bens, serviços e renda - As duas empresas têm a produção verticalizada, ou seja, cada uma é responsável pela produção integral dos produtos. Ambas são de pequeno porte, trabalham com pouca escala de produção e baixo nível de inovação. Devem fazer parcerias para melhorar sua gestão e ganhar mercados que isoladamente não conseguem atingir.

- Conhecimento - As duas empresas têm tamanhos e estruturas semelhantes e trabalham no mesmo mercado, mas não concorrem diretamente. Podem se beneficiar de trocas de informações sobre fornecedores, clientes, oportunidades de negócios, processos de produção, gerenciamento e comercialização, serviços empresariais, crédito, novas tecnologias, materiais, equipamentos, etc.

- Benefícios intangíveis - As duas empresas podem se beneficiar muito de uma maior interação e cooperação entre ambas, aprendendo uma com a outra e superando obstáculos de produção, gerenciamento ou comercialização - que teriam mais dificuldade de superar isoladamente. Podem fazer compras, realizar treinamentos e até mesmo terem espaços de comercialização em conjunto, desenhar estratégias de lançamento e distribuição de produtos e criar uma marca comum para seus produtos. Com isso, geram também um ambiente de confiança contribuindo para um maior senso de comunidade no APL e facilitando o compartilhamento do conhecimento essencial para o fortalecimento da rede.

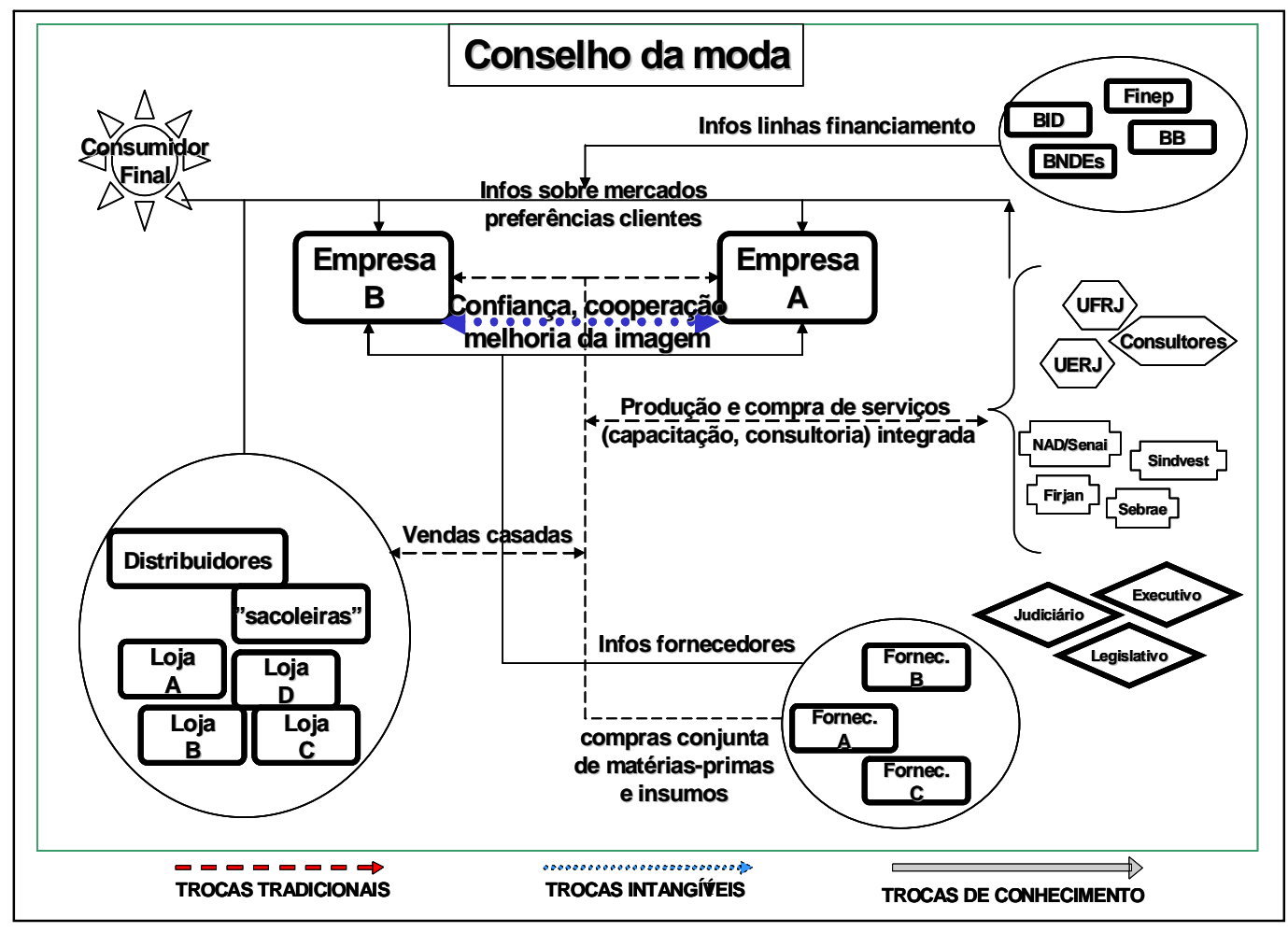

Liinc em Revista, v.2, n.2, setembro 2006, p.134-151 http://www.ibict.br/liinc 
Figura 3 - Diagrama das trocas de valor potenciais entre as empresas A e B

Fonte: Própria

Já o mapeamento das trocas reais entre esses atores ficou assim (Figura 4):

\section{Mapeamento das trocas existentes:}

- Bens, serviços e renda - A empresa A e a empresa B trabalham de forma isolada e não há nenhuma troca de bens, serviços e renda entre elas.

- Conhecimento - As empresas trabalham isoladamente, não havendo nenhuma troca de informação técnica, gerencial ou de mercado entre elas. As empresas tampouco compartilham dificuldades de acesso a crédito e serviços empresariais e de logística. Apesar de produzirem produtos complementares, não prospectam mercados comuns.

- Benefícios intangíveis - Por trabalharem isoladamente, não há troca de moedas intangíveis entre as empresas. Não há reforço de senso de comunidade, fidelidade de clientes comuns, uso conjunto de marcas, etc.

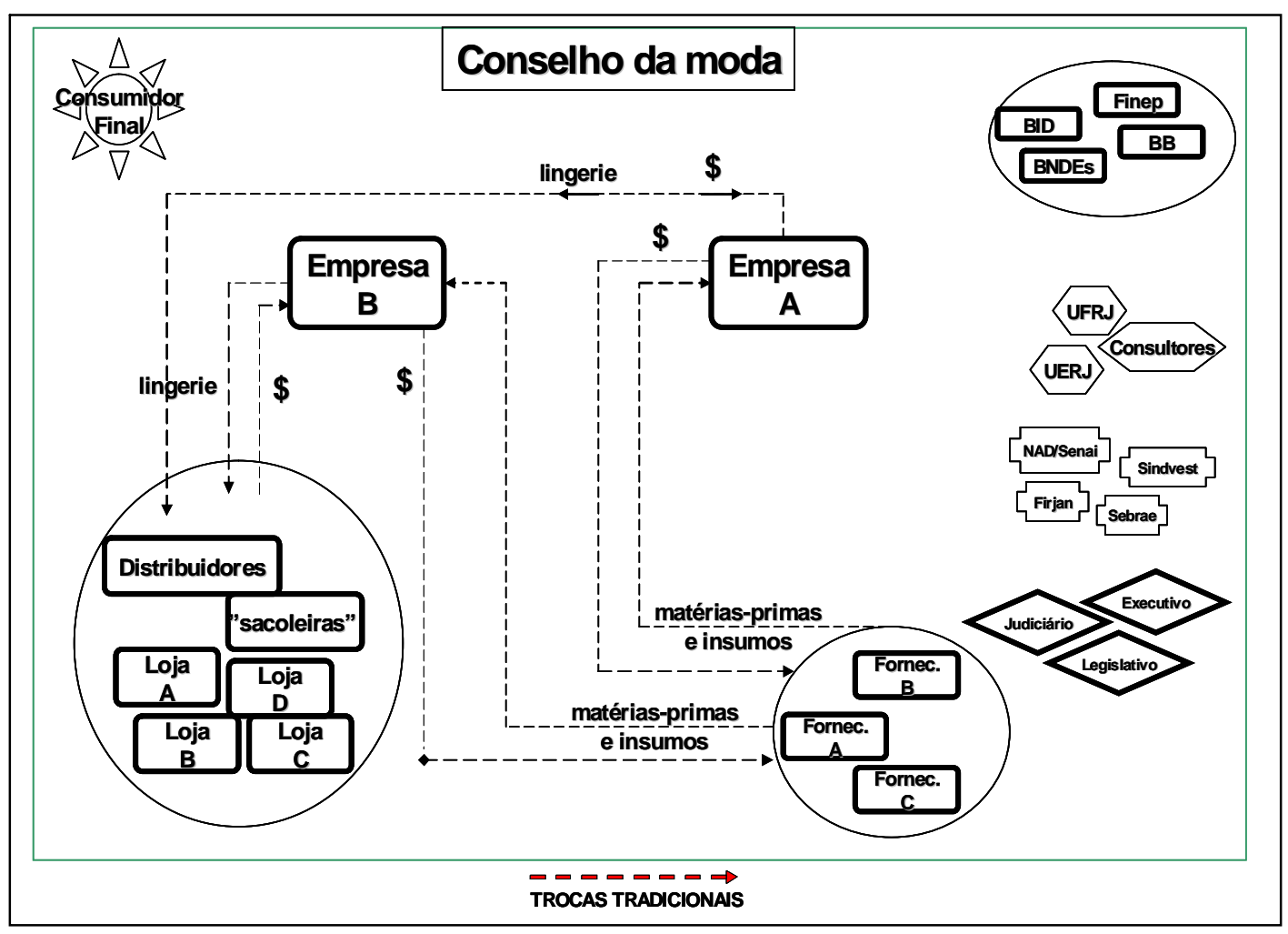


Figura 4 - Diagrama das trocas de valor existente entre as empresas A e B

Fonte: Própria

Confrontando-se essas trocas de valor existentes entre as empresas A e B com as que seriam necessárias para que as empresas atingissem seus objetivos estratégicos, chega-se às lacunas nas trocas de valor entre elas. Assim, a análise revela, por exemplo, que existem falhas nas trocas de conhecimento (inexistência de trocas de informações sobre melhores práticas de produção, gerenciamento e comercialização dos produtos, etc.) e nos benefícios intangíveis (baixa confiança e nenhuma cooperação entre as empresas). Percebe-se que as relações entre as empresas analisadas são pouco sofisticadas e pautadas exclusivamente por relações de mercado, no caso pela competição pura e simples. Elas não contemplam ações cooperativas, tais como treinamentos conjuntos e desenvolvimento de processos compartilhados, por exemplo, que thes trariam grandes benefícios intangíveis como informação, know-how, capacitação, experiência, reforço de imagem, reconhecimento, etc.

Façamos, agora, o mapeamento das trocas de moedas de valor entre outros dois atores, uma empresa de confecção de moda íntima e uma "sacoleira" (Figura 5).

\section{Mapeamento das trocas necessárias e potenciais:}

- Bens, serviços e renda - A confecção produz lingerie da linha aeróbica e a vende para a "sacoleira" para revenda a seus clientes finais. As trocas comerciais entre ambas podem trazer beneficios financeiros para as duas partes.

- Conhecimento - A "sacoleira" tem uma grande carteira de clientes e pode fornecer informações importantes sobre suas demandas para a confecção produzir sua lingerie de acordo com as expectativas do consumidor final. Com uma maior interação com a "sacoleira", sua rede de clientes passa a integrar a rede da própria confecção.

- Benefícios intangíveis - Ambas as partes podem se beneficar muito de uma maior interação. Aumenta a confiança da confecção na "sacoleira", que é vista como uma parceira no negócio da confecção. Sentindo-se parte integrante da rede, a "sacoleira" tem sua auto-estima melhorada e sente-se motivada a contribuir com informações (sugestões, reclamações, preferências) de sua rede de clientes. Essas informações trazidas pela "sacoleira" sobre as demandas do consumidor final, por sua vez, levam a confecção a produzir produtos de maior aceitação no mercado, que trazem maior satisfação ao cliente da "sacoleira", que dessa forma torna-se fiel à marca da empresa. 


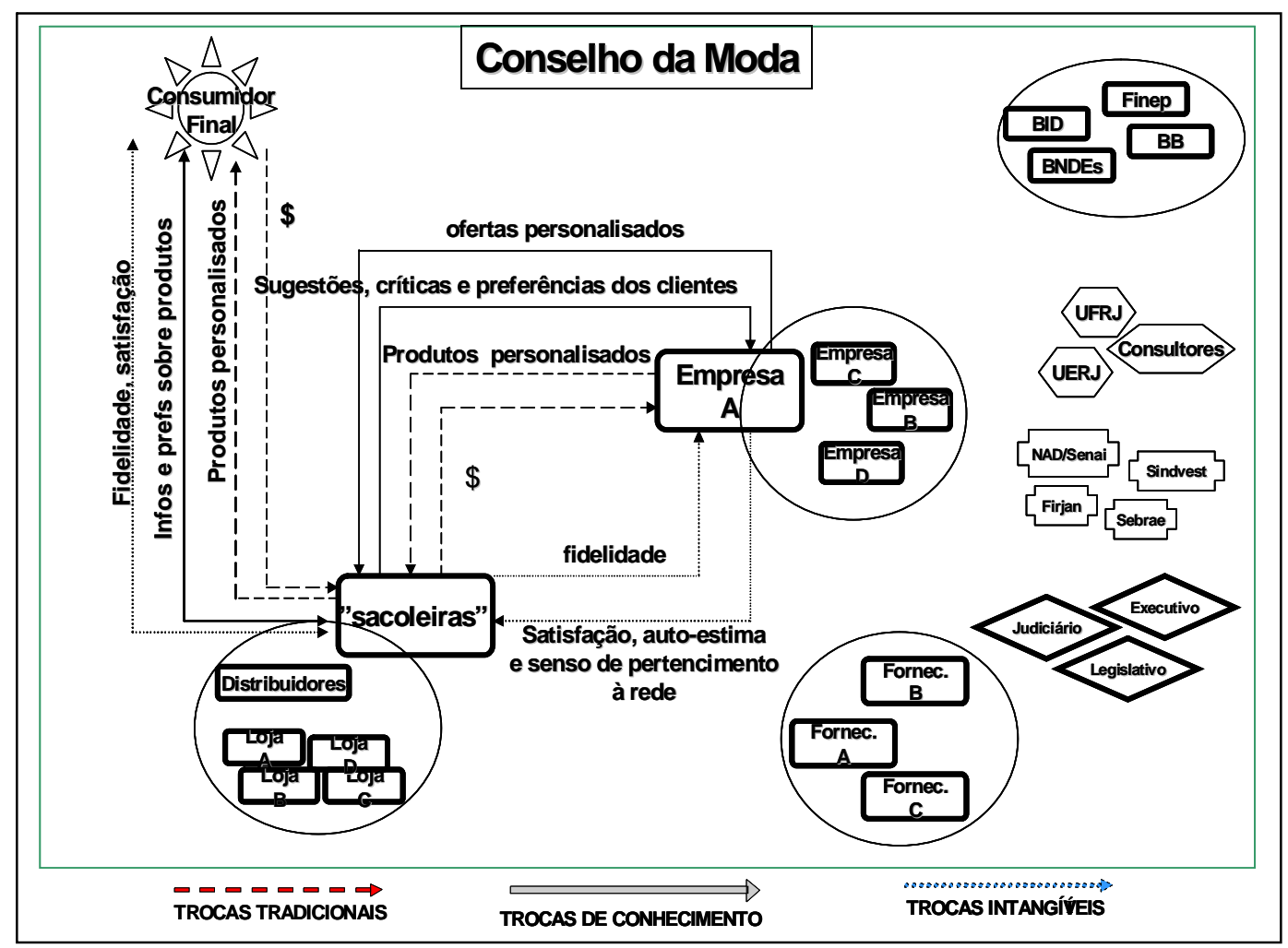

Figura 5 - Diagrama das trocas de valor necessárias e potenciais (tradicionais, de conhecimento e intangíveis) entre a empresa A e as "sacoleiras"

Fonte: Própria

Mapeamento das trocas existentes (Figura 6):

- Bens, serviços e renda - A "sacoleira" compra os produtos da confecção e os revende para seus clientes finais. A confecção recebe em troca o pagamento pela venda.

- Conhecimento - A confecção não tem nenhuma informação sobre os clientes da "sacoleira", que dessa forma nem fazem parte da rede da empresa. Tampouco tem informações sobre a própria "sacoleira" (de onde vem, para onde vai, para quem vende, etc). Não tem nenhuma noção das dificuldades que ela enfrenta para revender seus produtos às consumidoras finais, não acompanha sua trajetória nem se importa em saber se ela vai voltar ou não. Apenas vende para a "sacoleira" o que existe disponível na prateleira. 
- Benefícios intangíveis - Por trabalharem isoladamente, não há troca de moedas intangíveis entre as partes. Não há reforço de senso de comunidade, fidelidade de clientes comuns, ou senso de confiança entre os dois atores.

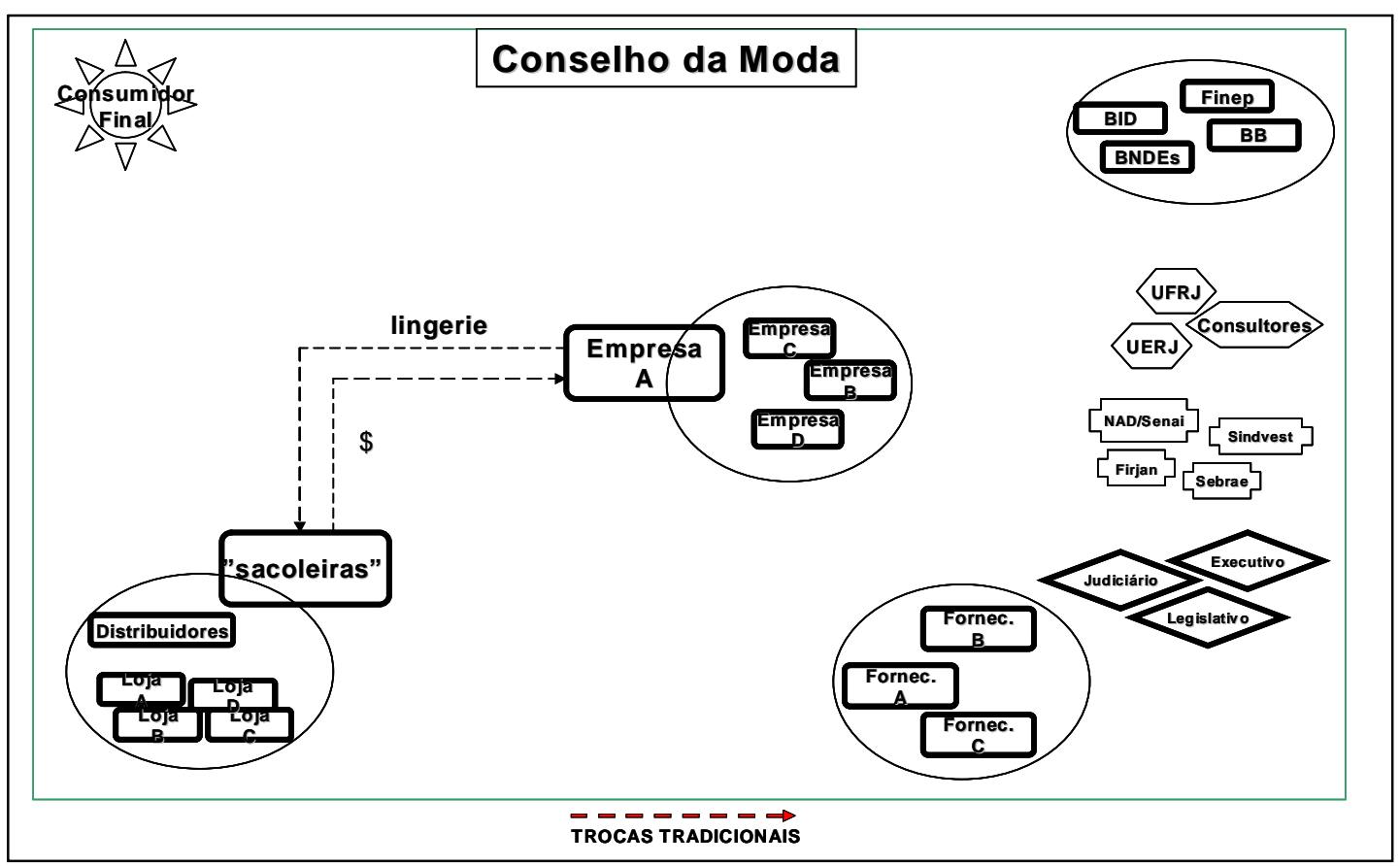

Figura 6 - Diagrama das trocas de valor existente entre a empresa A e as "sacoleiras"

Fonte: Própria

A análise das trocas de valor entre a empresa e a "sacoleira" revela um nível de relacionamento muito primário e meramente comercial. A "sacoleira" encontra na confecção produtos a preços, qualidade e em condições que considera satisfatórios e os compra para revender com uma margem de lucro que lhe interessa. Para o confeccionista a "sacoleira" é apenas mais um cliente. Ela compra sempre um número pequeno de peças, apesar de pagar corretamente. O confronto entre as trocas potenciais e as existentes revela profundas falhas de relacionamento entre esses dois atores do pólo. Por não trabalharem em parceria, a "sacoleira" não se sente parte integrante do pólo e não contribui com nenhuma informação que possa melhorar os produtos dos confeccionistas e, por conseguinte, sua competitividade. O confeccionista, por sua vez, despreza a figura da "sacoleira", por considerá-la um comprador menor e menos importante do que os grandes magazines, por exemplo.

\section{Estratégia de relacionamento e plano de ação}


A partir da análise das trocas de valor entre os atores do pólo, a instância de governança do APL, no caso o Conselho de Moda, parte para a gestão proporiamente dita do relacionamento entre eles. O Conselho de Moda pode manter um comitê de gestão do conhecimento que se responsabilize pela aplicação da metodologia de gestão do capital de relacionamento que o permitirá identificar as lacunas de interação, desenhar estratégias de relacionamento que aumentem a interação e a confiança entre eles e propor ações para preencher essas lacunas.

No caso das empresas do primeiro exemplo, a que produz lingerie dia e a que fabrica lingerie noite, a análise aponta para a necessidade de criação de uma central de compras do pólo, como uma ação de curto prazo no APL. Essa central teria por função agrupar os pedidos de matériaprima e insumos dos confeccionistas e negociar preços e condições de pagamento mais favoráveis junto a fornecedores. Agrupados, os confeccionistas têm mais poder de negociação e podem negociar melhores preços e condições de pagamento. Ao induzir essas trocas de bens, serviços e renda, o APL também estará promovendo as trocas de benefícios intangíveis, como confiança e senso de comunidade na rede. Na medida em que os processos de produção são iguais, as duas empresas também devem compartilhar treinamentos.

Como ação de médio prazo, o APL deve identificar as necessidades de capacitação dessas empresas e promover, através de suas instituição de apoio, como Sebrae, Senai e as universidades, cursos para a capacitação para seus gestores e funcionários. Também os canais de distribuição podem ser compartilhados, já que as duas empresas trabalham para o mesmo mercado, com produtos complementares, outra ação que deve ser desenvolvida a médio prazo.

Já num nível mais sofisticado de cooperação, numa ação de longo prazo, o APL pode promover o compartilhamento de equipamentos e tecnologias a que os confeccionistas isolados não têm acesso, nos mesmos moldes do que já é feito atualmente pelo Núcleo de Apoio ao Design (NAD) do Senai.

No caso do relacionamento da confecção com a "sacoleira", um primeiro passo para melhorar o relacionamento com os clientes e com o ambiente em que está inserido seria o APL capitalizar a figura da "sacoleira", responsável por boa parte das vendas da produção do pólo pelo Brasil afora. Atualmente, existe grande esforço de exportação das peças de lingerie produzidas em Nova Friburgo, mas o mercado interno, responsável pela grande maioria das vendas, é pouco trabalhado. Nele, as "sacoleiras" desempenham papel fundamental, já que respondem por 15,5\% das vendas. Mas, em vez de serem vistas como grandes aliadas, elas são tratadas como um resíduo, um ator menor, quase um mal necessário. O próprio termo "sacoleira" está eivado de preconceito. Essa profissional tem muito a contribuir com o pólo, fazendo a ponte entre os confeccionistas e os consumidores finais, fornecendo informações preciosas sobre as necessidades, desejos e aceitação dos clientes em relação ao que se produz no pólo de moda íntima de Friburgo.

Uma proposta que resulta da análise das trocas de valor nesse caso seria uma ampla campanha, entre os confeccionistas e entre as próprias "sacoleiras", de valorização da imagem dessas profissionais, transformando-as em "representantes do Pólo de Moda Íntima de Friburgo", como acontece com as revendedoras da Natura, por exemplo. Isso representaria um importante elemento de valorização de sua auto-estima e de seu papel como aliada do pólo, melhorando sobremaneira a relação entre elas e os confeccionistas, e, por conseguinte, nos resultados de venda do mercado interno. O primeiro passo nesse sentido é cadastrar todas as representantes, com informações detalhadas sobre elas e os mercados onde atuam e em seguida desenvolver uma ampla campanha de marketing pró "representante", mudando a visão sobre essa profissional. 
Juntamente com a campanha, o pólo deve desenvolver treinamentos e cursos diretamente voltados para essas profissionais, como técnicas de venda, relacionamento com clientes, etc.

Uma ação que deve ser desenvolvida a médio e longo prazo é a utilização das informações trazidas por essas representantes sobre os clientes finais para a co-criação de novos produtos, mais adequados aos desejos e necessidades dos consumidores, e serviços e campanhas promocionais para atração e fixação de clientes no pólo, como programas de "milhagem" e fidelidade à marca "moda íntima de Friburgo".

A adoção desse instrumental permite que se olhem as relações entre os membros do pólo com outros olhos, vislumbrando ações com grande potencial de estreitamento dos vínculos ali existentes. A idéia da metodologia apresentada é que se faça um mapeamento e análise das trocas potenciais e existentes entre todos os atores-chave para o APL, identificando as lacunas que permitirão o desenho de estratégias e planos de ação em prol de um melhor relacionamento na rede.

\section{Conclusões}

O presente trabalho teve por objetivo apresentar uma proposta de metodologia para a gestão do capital de relacionamento em um arranjo produtivo local, num contexto marcado pela informacionalização da economia, a preponderância do conhecimento como fator de produção e a presença crescente de redes no ambiente organizacional. Nesses ambientes, as redes se tornaram importantes variáveis estratégicas, afetando fortemente as formas de competição.

No caso de arranjos produtivos locais brasileiros, essa constatação é mais do que urgente, por se tratar de redes de micro e pequenas empresas, que atuam, freqüentemente, na informalidade e no limite da subsistência, pela imensa dificuldade de acesso a serviços essenciais para a melhoria da qualidade dos seus negócios.

Mesmo em APLs com certo nível de formalização, como o de moda íntima de Nova Friburgo, que dispõe de uma instância de governança (o Conselho de Moda) e onde atuam diversas instituições de fomento e apoio, a cooperação entre os agentes, conforme demonstram diversos estudos ali realizados, é bastante fraca. E a cooperação é apontada como elemento essencial para o fortalecimento dessas configurações produtivas. Somente a união é capaz de garantir-lhes as vantagens da produção em escala de uma grande empresa e o acesso a benefícios impossíveis de serem atingidos isoladamente.

Como se chega a isso, porém, é um dos grandes desafios para os formuladores e gestores de políticas públicas voltadas para o desenvolvimento local. De que forma se consegue que micro e pequenos empresários, que vivem um dia-a-dia de feroz competição pela sobrevivência, tomem consciência da importância da cooperação?

A nosso ver, um dos caminhos possíveis é fazer com eles percebam o valor real que essas interações têm para seus próprios negócios. Partimos do pressuposto de que o que move as pessoas e instituições a se reunirem são interesses comuns. É preciso que elas tenham claros esses interesses para se mobilizarem em direção ao outro. E esses interesses vão muito além das trocas comerciais, de bens, serviços e renda, que se estabelecem entre eles. À medida que mais e mais produtos e serviços dependem da troca de informação e conhecimento, o conhecimento e os 
benefícios intangíveis que advêm das interações tornam-se, eles próprios, valiosas moedas de troca. Os agentes dos APLs precisam ver claramente que as trocas financeiras resultantes das transações comerciais são apenas parte do quadro, apenas a ponta de um grande iceberg. Outra parte, até maior, do valor das interações está na troca de conhecimento e de benefícios intangíveis, e o sucesso depende de se construir uma rica teia de relacionamentos de confiança.

A metologia que apresentamos neste trabalho visa uma melhor gestão do capital de relacionamento nos APLs. Daí o seu foco na identificação dos valores percebidos pelos atores da rede, fugindo de um discurso genérico sobre a importância da cooperação e do desenvolvimento regional. Ela desnuda não só as trocas de valores econômicos, mas também informação, conhecimento e benefícios intangíveis, como confiança, amizade, reconhecimento social, senso de comunidade, qualidade de vida e muitos outros que têm peso preponderante no ambiente econônico e social dos nossos dias. Tendo claro o valor dessas trocas, parte-se para o desenho de estratégias de relacionamentos e planos de ação que possibilitem estreitar esses laços e, por conseguinte, aumentar o potencial de sucesso dos APLs, visando o desenvolvimento local sustentável.

\section{Referências}

ALBAGLI, S; MACIEL, M L. Informação e conhecimento na inovação e no desenvolvimento local. Ciência da Informação, Brasília: Ibict, v. 33, n. 3, 2004.

ALLEE, V. Novas Ferramentas para uma Nova Economia. Inteligência Empresarial, Rio de Janeiro: Centro de Referência em Inteligência Empresarial $\quad$ n. 3, 2000.

Reconfigurando a rede de valor. Inteligência Empresarial, Rio de Janeiro: Centro de Referência em Inteligência Empresarial n. 16, 2003.

CASTELLS, M. A sociedade em rede, 1: a era da informação: economia, sociedade e cultura. São Paulo: Paz e Terra, 1999.

CAVALCANTI, M.; GOMES, E.; PEREIRA, A. Gestão de empresas na sociedade do conhecimento: um roteiro para a ação. Rio de Janeiro: Campus, 2001.

FAURÉ, Y; HASENCLEVER, L. O desenvolvimento local no estado do Rio de Janeiro: estudos avançados nas realidades municipais. Rio de Janeiro: E-Papers Serviços Editoriais, 2005.

IETS. Criação de um ambiente favorável aos micro e pequenos negócios e desenvolvimento. Rio de Janeiro, 2002. Policy Paper n. 2.

LASTRES, H; ALBAGLI, S. (Org.) Informação e globalização na era do conhecimento. Rio de Janeiro: Campus, 1999.

LASTRES, H.; CASSIOLATO, J. E.; ARROIO, A. (Org.). Conhecimento, sistemas de inovação e desenvolvimento. Rio de Janeiro: Ed. UFRJ: Contraponto, 2005. 
LAUFER, A.; FURTADO, A. P.; BATISTA NETO, A. APL de moda íntima de Nova Friburgo: aplicação de conceitos. Rio de Janeiro, 2005. Trabalho de final de curso da disciplina Tópicos Especiais em Gestão do Conhecimento, apresentado na Coppe/UFRJ.

PEREIRA NETO, A; CAVALCANTI, M; LIMA, R. Gestão do conhecimento em arranjos produtivos locais: o caso de Nova Friburgo. Produto \& Produção, Porto Alegre: UFRGS, v. 8, n. 3, 2005. 